\title{
Impulsion of induced magnetic field for Brownian motion of nanoparticles in peristalsis
}

\author{
Noreen Sher Akbar' ${ }^{1}$ M. $\operatorname{Raza}^{2} \cdot$ R. Ellahi ${ }^{2,3}$
}

Received: 14 February 2015/ Accepted: 9 April 2015/Published online: 10 May 2015

(c) The Author(s) 2015. This article is published with open access at Springerlink.com

\begin{abstract}
In the present study, we examined the effect of induced magnetic field for the peristaltic flow of four different nanoparticles with the base fluid water in the presence of Brownian motion, in a vertical asymmetric channel. The mathematical formulation is presented. Exact solutions have been evaluated for the resulting equations. The obtained expressions for velocity, temperature, pressure gradient and magnetic force function are described through graphs for various pertinent parameters. The streamlines are drawn for some physical quantities to discuss the trapping phenomenon.
\end{abstract}

Keywords Induced MHD - Peristaltic flow · Nanofluid · Brownian motion - Asymmetric channel $\cdot$ Heat generation

\section{Introduction}

It is observed that heat transfer can be augmented through the improvement in the thermal properties of energy transmission fluids. If small solid particles in the fluid are suspended, then this might be an innovative way of improving the thermal conductivities of fluids. Nanofluids are estimated to show conventional heat transfer fluids as

M. Raza

mohsinvirgo18@gmail.com

1 DBS\&H, CEME, National University of Sciences and Technology, Islamabad, Pakistan

2 Department of Mathematics and Statistics, FBAS, IIU, Islamabad 44000, Pakistan

3 Department of Mechanical Engineering, Bourns Hall A 373, University of California Riverside, Riverside, CA 92521, USA compared with superior heat transfer properties. Jou and Tzeng (2006) reported a numerical study of the heat transfer performance of nanofluids inside $2 \mathrm{D}$ rectangular enclosures. Their results express that a considerable enhancement of the average rate of heat transfer is produced by increase in the volume fraction of nanoparticles. This idea of suspensions of colloidal particles dubbed as nanofluids was given by Choi (1995). He was of the view that small amounts of metallic or metallic oxide nanoparticles are dispersed into water and other fluids. Detailed reviews have explained that (Sheikholeslami and GorjiBandpy 2014; Sheikholeslami et al. 2014a), in the previous decade, the model mechanisms of thermal conductivity enhancement of nanofluids have been identified in different ways, along with the size and shape of the nanoparticles, the hydrodynamic interaction between nanoparticles and base fluid, clustering of particles, temperature or Brownian motion and so on. If movement of nanoparticles is supposed to be considered, there has to be some contribution of a dynamic component related to particle Brownian motions in their model development according to some researchers. (Sheikholeslami et al. 2012a, b, 2013; Koo and Kleinstreuer Koo and Kleinstreuer 2004a, b; Palm et al. 2006; Akbarinia and Behzadmehr 2007).

Peristalsis is a mechanism of fluid that flows through movement of contraction on the tubes/channels walls. First of all, this concept was developed by Latham (1966). He described fluid motion in a peristaltic pump. Further, he also explained the characteristic of pressure rise versus flow rate. After the pioneering work of Latham (1966), Jaffrin and Shapiro (1971) investigated peristaltic pumping. They showed the analysis under the assumption of long wavelength and low Reynolds number approximations. After that, too much analytical, numerical and experimental research of peristaltic flows of different fluids came into existence under 
different conditions with reference to physiological and mechanical situations. Peristaltic pumping by a sinusoidal traveling wave in the porous walls of a two-dimensional channel filled with a viscous incompressible conducting fluid under the effect of a transverse magnetic field was investigated theoretically and graphically by El-Shehawey and Husseny (2002). The effects of magnetohydrodynamics (MHD) on peristaltic flow problems also have some applications in physiological fluids such as blood flow, blood pump machines and theoretical studies on the operation of peristaltic MHD compressors. Moving magnetic field effects on blood flow was studied by Sud et al. (1997). They found that the effects of moving magnetic field accelerate the speed of the blood. Srivastava and Agrawal (1980) consider blood as an electrically conducting fluid constituting a suspension of red cells in plasma. Li et al. (1994) considered an impulsive magnetic filed in the combined therapy of patients with stone fragments in the upper urinary tract. It was discovered that the impulsive magnetic field activates the impulsive activity of the uretaral smooth muscles in $100 \%$ of cases. Mekheimer and Al-Arabi (2003) investigated the nonlinear peristaltic transport of MHD flow through a porous medium in nonuniform channels. The peristaltic transport of blood under the effect of a magnetic field in nonuniform channels was studied by Mekheimer (2004). Further literature can be viewed through other references (Mekheimer 2008a, b; Akbar et al. 2014a; Koo and Kleinstreuer 2004b; Abu-Nada 2010; Ghasemi and Aminossadati 2010; Koo and Kleinstreuer 2005; Nadeem et al. 2014a; Ibrahim and Hamad 2006; Abu-Nada 2009; Jang and Choi 2007; Akbar and Khan 2015; Ellahi et al. 2014; Akbar et al. 2014b;Nadeem et al. (2014b, c) Akbar 2014; Sheikholeslami et al. 2015; Sheikholeslami et al. 2014a, b; Sheikholeslami and Gorji-Bandpy 2014)

The aim of this study is to look at the effects of induced magnetic field on the peristaltic flow of four different nanoparticles with the base fluid water in the presence of Brownian motion, in a vertical asymmetric channel. The selected nanoparticles are copper oxide $(\mathrm{CuO})$, silver $(\mathrm{Ag})$, titanium dioxide $\left(\mathrm{TiO}_{2}\right)$ and copper $(\mathrm{Cu})$. Brownian motion shows that the effective thermal conductivity, consisting of the particles' conventional static part and the Brownian motion part, increases resulting in a lower temperature gradient for a given heat flux. To understand these transport phenomena thoroughly, we consider the thermal conductivity model (Mekheimer 2008a) for nanofluids, which considers the effects of particle size, particle volume fraction and temperature dependence. The mathematical formulation is presented; and the exact solution for the stream function, magnetic force function, temperature and pressure gradient is given. All the physical features of the problems have been described with the help of graphs.

\section{Mathematical formulation}

Here, we discussed an incompressible peristaltic flow of copper nanofluid in an irregular channel with channel width $d_{1}+d_{2}$. Asymmetry in the flow is because of propagation of peristaltic waves of different amplitudes and phases on the channel walls. An external transverse uniform constant uniform constant magnetic field $H_{0}$, induced magnetic field $H\left[h_{X}(X, Y, t), H_{0}+h_{Y}(X, Y, t), 0\right]$ and the total magnetic field $H^{+}\left[h_{X}(X, Y, t), H_{0}+h_{Y}\right.$ $(X, Y, t), 0]$ are taken into account. Finally, the channel walls are considered to be nonconductive sinusoidal waves propagating beside the walls of the channel with continuous hustle $c_{1}$. The geometry of the wall surfaces is defined as follows:

$$
\begin{aligned}
& Y=\bar{H}_{1}=d_{1}+a_{1} \cos \left[\frac{2 \pi}{\lambda}\left(\bar{X}-c_{1} \bar{t}\right)\right], \\
& Y=\bar{H}_{2}=-d_{2}-b_{1} \cos \left[\frac{2 \pi}{\lambda}\left(\bar{X}-c_{1} \bar{t}\right)+\omega\right] .
\end{aligned}
$$

In the above equations $a_{1}$ and $b_{1}$ denote the wave amplitudes, $\lambda$ is the wavelength, $d_{1}+d_{2}$ is the channel width, $c_{1}$ is the wave speed, $\bar{t}$ is the time, $\bar{X}$ is the direction of wave propagation and $Y$ is perpendicular to $\bar{X}$.

Equations governing the flow and temperature in the presence of heat source or heat sink and the equation which governs the MHD flow are given as

(i) Maxwell's Eqs. (19, 20, 21):

$\nabla \cdot H=0, \quad \nabla \cdot E=0$,

$\nabla \wedge H=J, \quad J=\sigma\left\{E+\mu_{\mathrm{nf}}(V \wedge H)\right\}$,

$\nabla \wedge E=-\mu_{\mathrm{nf}} \frac{\partial H}{\partial t}$.

(ii) The continuity equation:

$\nabla \cdot V=0$.

(iii) The equations of motion:

$$
\begin{aligned}
\rho_{\mathrm{nf}}\left(\frac{\partial V}{\partial t}+V \cdot \nabla V\right)= & -\nabla p+\mu_{\mathrm{nf}} \operatorname{div} V \\
& +(\rho \beta)_{\mathrm{nf}} g \alpha\left(T-T_{0}\right) \\
& -\nabla\left(\frac{1}{2} \mu_{\mathrm{nf}}\left(H^{+}\right)^{2}\right) \\
& -\mu_{\mathrm{nf}}\left(H^{+} \cdot \nabla\right) H .
\end{aligned}
$$

(iv) The energy equation:

$(\rho c)_{\mathrm{f}}\left(\frac{\partial T}{\partial t}+V \cdot \nabla T\right)=\nabla \cdot k_{\mathrm{nf}} \nabla T+Q_{0}\left(T-T_{\infty}\right)$.

Combining Eqs. (2) to (4), we obtain the induction equation $[19,20,21]$ as follows: 
$\frac{\partial H^{+}}{\partial t}=\nabla \wedge\left(V \wedge H^{+}\right)+\frac{\mu_{\mathrm{nf}}}{\mu_{\mathrm{f}}} \frac{1}{\xi} \nabla^{2} H^{+}$,

where $\zeta=\frac{1}{\sigma \mu_{\mathrm{H}}} N$ is the magnetic diffusively, $\rho_{\mathrm{nf}}$ is the effective density of the incompressible fluid, $(\rho c)_{\mathrm{nf}}$ is the heat capacity of the fluid, $(\rho c)_{p}$ gives effective heat capacity of the nano particle material, $k_{\mathrm{nf}}$ implies effective thermal conductivity, $g$ stands for constant of gravity, $\mu_{\mathrm{nf}}$ is the effective viscosity of the fluid, $\mathrm{d} / \mathrm{d} t$ gives the material time derivative and $P$ is the pressure. The appearance of static and wave structures are connected by the subsequent associations:

$x=X-c t, y=Y, u=U-c, v=V$.

The dimensionless parameters used in the problem are defined as follows:

$$
\begin{aligned}
& \bar{p}=\frac{a^{2}}{\mu_{\mathrm{f}} c \lambda} p, \bar{u}=\frac{\lambda}{a c} u, \bar{v}=\frac{v}{c}, \bar{y}=\frac{y}{\lambda}, \bar{x}=\frac{x}{a}, \bar{t}=\frac{c}{\lambda} t, \omega=\frac{b}{a}, \\
& R e=\frac{\rho c a}{\mu_{\mathrm{f}}}, \delta=\frac{a}{\lambda}, \bar{\theta}=\frac{T-T_{0}}{T_{1}-T_{0}}, \bar{\Phi}=\frac{\Phi}{H_{0} a}, \bar{\Psi}=\frac{\Psi}{c a}, R_{\mathrm{m}}=\sigma \mu_{\mathrm{f}} a c, \\
& G_{r}=\frac{\rho_{f} g \alpha a^{2}}{\mu_{\mathrm{f}} c}\left(T_{1}-T_{0}\right), S_{1}=\frac{H_{0}}{c} \sqrt{\frac{\mu_{\mathrm{f}}}{\rho}}, \alpha_{\mathrm{nf}}=\frac{k_{\mathrm{nf}}}{\left(\rho c_{\mathrm{p}}\right)_{\mathrm{nf}}}, \tau=\frac{(\rho c)_{\mathrm{p}}}{(\rho c)_{\mathrm{f}}} .
\end{aligned}
$$

After using the above nondimensional parameters and transformation in Eq. (9) employing the assumptions of long wavelength $(\delta \rightarrow 0)$, the dimensionless governing equations (without using bars) for nanofluid in the wave frame take the final form as

$\frac{\partial u}{\partial x}+\frac{\partial v}{\partial y}=0$

$\frac{\mathrm{d} p}{\mathrm{~d} x}=\frac{\mu_{\mathrm{nf}}}{\mu_{\mathrm{f}}} \frac{\partial^{3} \Psi}{\partial y^{3}}+R e S_{1}^{2} \Phi_{\mathrm{yy}}+G_{\mathrm{r}} \frac{(\rho \beta)_{\mathrm{nf}}}{(\rho \beta)_{\mathrm{f}}} \theta$,

$\frac{\mathrm{d} p}{\mathrm{~d} y}=0$,

$\Phi_{y y}=\frac{\mu_{\mathrm{nf}}}{\mu_{\mathrm{f}}} R_{\mathrm{m}}\left(E-\frac{\partial \Psi}{\partial y}\right)$,

$\frac{k_{\mathrm{nf}}}{k_{\mathrm{f}}} \frac{\partial^{2} \theta}{\partial y^{2}}+Q_{o} \theta=0$.

Combining Eq. (14) and Eq. (12) we get

$\frac{\mathrm{d} p}{\mathrm{~d} x}=\frac{\mu_{\mathrm{nf}}}{\mu_{\mathrm{f}}} \frac{\partial^{3} \Psi}{\partial y^{3}}+R e S_{1}^{2} \frac{\mu_{\mathrm{nf}}}{\mu_{\mathrm{f}}} R_{\mathrm{m}}\left(E-\frac{\partial \Psi}{\partial y}\right)+G_{\mathrm{r}} \frac{(\rho \beta)_{\mathrm{nf}}}{(\rho \beta)_{\mathrm{f}}} \theta$.

Taking the derivative of the above equation with respect to $y$, finally we get

$\frac{\mu_{\mathrm{nf}}}{\mu_{\mathrm{f}}} \frac{\partial^{4} \Psi}{\partial y^{4}}+R e S_{1}^{2} \frac{\mu_{\mathrm{nf}}}{\mu_{\mathrm{f}}} R_{\mathrm{m}}\left(-\frac{\partial^{2} \Psi}{\partial y^{2}}\right)+G_{\mathrm{r}} \frac{(\rho \beta)_{\mathrm{nf}}}{(\rho \beta)_{\mathrm{f}}} \frac{\partial \theta}{\partial y}=0$.
The nondimensional boundaries take the form

$\Psi=\frac{F}{2}, \quad \frac{\partial \Psi}{\partial y}=-1$, at $y=h_{1}$.

$\Psi=-\frac{F}{2}, \frac{\partial \Psi}{\partial y}=-1$, at $y=h_{2}$.

$\theta=0$ at $y=h_{1}, \theta=1$ at $y=h_{2}$,

$\Phi=0$ at $y=h_{1}, \Phi=0$ at $y=h_{2}$.

The thermophysical properties, obtained from AbuNada (2010) and Ghasemi and Aminossadati (2010)) for pure water, copper oxide, silver, titanium dioxide and copper at room temperature are listed in Table 1. The effective density $\rho_{\mathrm{nf}}$, specific heat $\left(c_{\mathrm{p}}\right)_{\mathrm{nf}}$ and thermal expansion coefficient $\beta_{\mathrm{nf}}$ of nanofluids are given by

$$
\begin{aligned}
\rho_{\mathrm{nf}} & =(1-\varphi) \rho_{\mathrm{f}}+\varphi \rho_{\mathrm{f}}, \\
\left(\rho c_{\mathrm{p}}\right)_{\mathrm{nf}} & =(1-\varphi)\left(\rho c_{\mathrm{p}}\right)_{\mathrm{f}}+\varphi\left(\rho c_{\mathrm{p}}\right)_{\mathrm{s}}, \\
(\rho \beta)_{\mathrm{nf}} & =(1-\varphi)(\rho \beta)_{\mathrm{f}}+\varphi(\rho \beta)_{\mathrm{s}},
\end{aligned}
$$

where the subscript nf, $f$ and $s$ stand for the nanofluid, base fluid and nanoparticle, respectively, and $\varphi$ is the solid volume fraction. It is observed that the above-mentioned properties of Eq. (22) are considered to be independent on the movement of nanoparticles. Brownian motion is claimed to play an important role in modifying the thermal conductivity and viscosity of nanofluids. Among the existing models that predict the thermal conductivity and viscosity of nanofluids considering Brownian motion, the models proposed by Koo and Kleinstreuer $(2004,2005)$ are utilized in the present study. These models have successfully been used by Ghasemi and Aminossadati (2010) to study the effects of Brownian motion on laminar steady-state natural convection in a right triangular enclosure with localized heating on the vertical side. Note that these models were proposed based on water with copper oxide nanoparticles. Although the extension to other combinations of base liquids and nanoparticles may be justified, the material of the nanoparticles being considered in the present study are limited to copper

\begin{tabular}{|c|c|c|c|c|c|}
\hline $\begin{array}{l}\text { Physical } \\
\text { properties }\end{array}$ & $\begin{array}{l}\text { Water } \\
\left(\mathrm{H}_{2} \mathrm{O}\right)\end{array}$ & $\mathrm{CuO}$ & $\mathrm{Ag}$ & $\mathrm{TiO}_{2}$ & $(\mathrm{Cu})$ \\
\hline$\rho$ & & $\left(\mathrm{kg} \mathrm{m}^{-3}\right)$ & 997.1 & 6500.0 & 10500.0 \\
\hline 4250.0 & 8933.0 & $\mathrm{Cp}$ & 4179.0 & 540.0 & 235 \\
\hline 686.2 & 385.0 & $\beta \times 10^{5}\left(\mathrm{~K}^{-1}\right)$ & 21.0 & 0.85 & 1.89 \\
\hline 0.90 & 1.67 & $k, \mathrm{Wm}^{-1}\left(\mathrm{~K}^{-1}\right)$ & 0.613 & 18.0 & 429.0 \\
\hline
\end{tabular}
oxide, silver, titanium dioxide and copper. In these models, it is assumed that the thermal conductivity and viscosity of

Table 1 Thermal-physical properties of water and nanoparticles (Nadeem et al. 2014a; Ibrahim and Hamad 2006; Abu-Nada 2009; Jang and Choi 2007; Akbar and Khan 2015; Ellahi et al. 2014) 
nanofluids consist of two parts. One is referred to as the static part $\left(k_{\mathrm{s}}, \mu_{\mathrm{s}}\right)$ that is evaluated by mixture models, i.e., the Maxwell model for thermal conductivity and the Brinkman model for viscosity (Ghasemi and Aminossadati $2010)$ and the other part $\left(k_{\mathrm{B}}, \mu_{\mathrm{B}}\right)$ is attributed to Brownian motion. The expression for predicting the effective thermal conductivity of nanofluids appears as

$k_{\mathrm{nf}}=k_{\mathrm{s}}+k_{\mathrm{B}}$

where $k_{s}$ is given by the Maxwell model

$k_{\mathrm{nf}}=k_{\mathrm{f}}\left(\frac{k_{\mathrm{s}}+2 k_{\mathrm{f}}-2 \varphi\left(k_{\mathrm{f}}-k_{\mathrm{s}}\right)}{k_{\mathrm{s}}+2 k_{\mathrm{f}}+2 \varphi\left(k_{\mathrm{f}}-k_{\mathrm{s}}\right)}\right)$

and $k_{B}$ is expressed as (Abu-Nada 2010)

$k_{\mathrm{B}}=5 \times 10^{4} \gamma \varphi\left(\rho c_{\mathrm{p}}\right)_{\mathrm{f}} \sqrt{\frac{\kappa T_{\text {env }}}{\rho_{\mathrm{s}} d_{\mathrm{s}}}} F\left(T_{\text {env }}, \varphi\right)$,

where $\kappa$ is the Boltzmann constant and its value is $\kappa \approx 1.38 \times 10^{-23} \mathrm{~J} / \mathrm{K}, d_{\mathrm{s}}$ is the diameter of nanoparticles by assuming that these nanoparticles have a uniform size and are perfectly spherical, i.e., $d_{\mathrm{s}}=30 \mathrm{~nm}, T_{\text {env }}$ is a reference temperature that is chosen as $T_{0}$ in the current study, $\gamma$ is a function of the volume fraction $\varphi$ of nanoparticles, which is given by

$\gamma= \begin{cases}0.0137(100 \varphi)^{-0.8229} & \text { for } \varphi<0.01 \\ 0.0011(100 \varphi)^{-0.7272} & \text { for } \varphi>0.01\end{cases}$

and the function $F\left(T_{\text {env }}, \varphi\right)$ is given by
$F\left(T_{\text {env }}, \varphi\right)=(-6.04 \varphi+0.4705) T_{\text {env }}$

which is valid for $0.01 \leq \varphi \leq 0.04$ and $300 \mathrm{~K} \leq T_{\text {env }}$ $\leq 325 \mathrm{~K}$.

We choose $T_{\mathrm{env}}=300 \mathrm{~K}$ in the present study, for the expression of thermal conductivity. The thermal diffusivity of nanofluids is then given by

$\alpha_{\mathrm{nf}}=\frac{k_{\mathrm{nf}}}{\left(\rho c_{\mathrm{p}}\right)_{\mathrm{nf}}}$.

Likewise, as given in (Koo and Kleinstreuer 2005), the effective viscosity of nanofluids is given by

$\mu_{\mathrm{nf}}=\mu_{\mathrm{s}}+\mu_{\mathrm{B}}$,

where $\mu_{\mathrm{s}}$ is evaluated by Brinkman model: $\mu_{\mathrm{s}}=\mu_{\mathrm{nf}}(1-$ $\varphi)^{-2.5}$ and $\mu_{\mathrm{B}}$ is expressed as

$\mu_{\mathrm{B}}=5 \times 10^{4} \gamma \varphi \rho_{\mathrm{nf}} \sqrt{\frac{\kappa T_{\text {env }}}{\rho_{\mathrm{s}} d_{\mathrm{s}}}} F\left(T_{\text {env }}, \mathrm{f}\right)$.

\section{Solution to the problem}

The exact solutions of the above equations are found as follows:

$\left.\theta(y)=\csc \left(\frac{\sqrt{Q_{0}} \sqrt{K_{\mathrm{f}}}(h 1-h 2)}{\sqrt{K_{\mathrm{nf}}}}\right) \sin \left(\frac{\sqrt{Q_{0}} \sqrt{K_{\mathrm{f}}}(h 1-y)}{\sqrt{K_{\mathrm{nf}}}}\right)\right)$, 


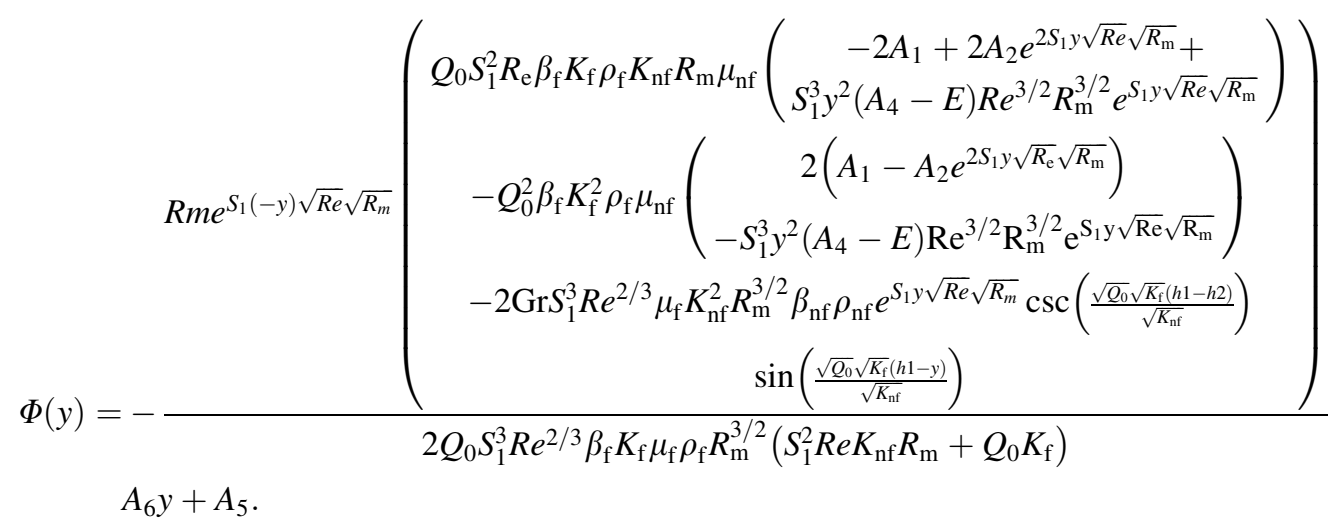

The mean volume flow rate $Q$ over one period is given as

$Q=F+1+d$

and the pressure gradient $\mathrm{d} p / \mathrm{d} x$ is elaborated as velocity and induced magnetic field. The expression for the pressure rise is calculated numerically using a mathematics software. The graphical results of the pressure rise, pressure gradient, temperature, magnetic force function and velocity are displayed in Figs. 1, 2, 3, 4 and 5 for all the

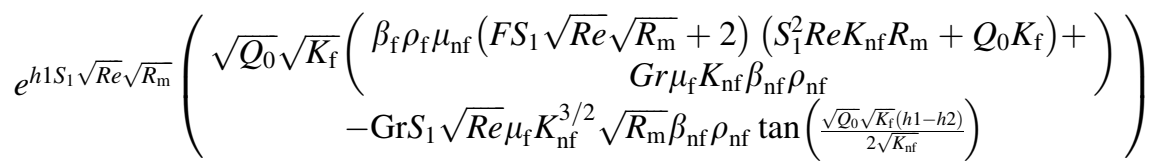

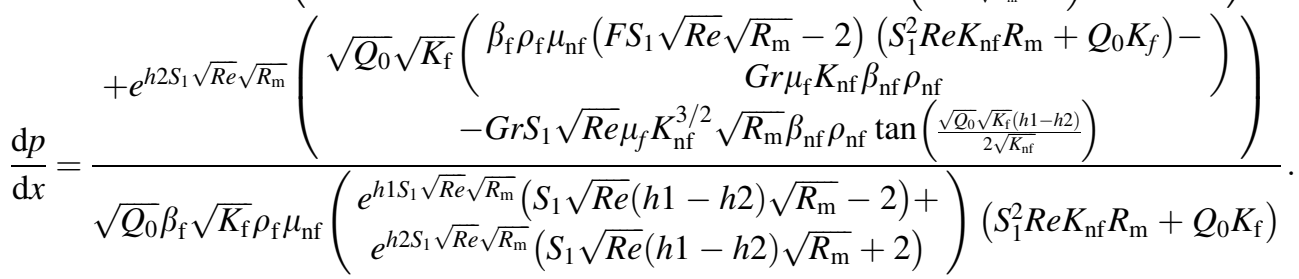

The pressure rise $\Delta p$ in nondimensional form is defined as

$$
\Delta p=\int_{0}^{1} \frac{\mathrm{d} p}{\mathrm{~d} x} \mathrm{~d} x .
$$

$A_{1}-A_{6}$ are constants evaluated using Mathematica 9.

\section{Results and discussions}

In this section, we have discussed all the obtained solutions graphically under the variations of various pertinent parameters on the profiles of pressure gradient, temperature, four type of fluids $\left(\mathrm{CuO}-\mathrm{H}_{2} \mathrm{O}, \mathrm{Ag}-\mathrm{H}_{2} \mathrm{O}, \mathrm{TiO}_{2}-\mathrm{H}_{2} \mathrm{O}, \mathrm{Cu}-\right.$ $\mathrm{H}_{2} \mathrm{O}$ ). The trapping bolus phenomenon observing the flow behavior is also manipulated as well with the help of streamline graphs in Figs. 6, 7 and 8.

In Fig. 1a-f we have shown the pressure rise against the flow rate $Q$ for different values of volume fraction $\varphi$, Strommer's number $S_{1}$, heat generation parameter $Q_{0}$, magnetic Reynolds number $R_{\mathrm{m}}$, Grashof number $G_{\mathrm{r}}$ and Reynolds number $R e$. Figure 1a represents the effects of volume fraction $\varphi$ on the pressure rise $\Delta p$. It is noticed here that pressure rise is an increasing function with the increase of $\varphi$ throughout the pumping region $(\Delta p>0)$; at the same time, $\Delta p$ decreases as $\varphi$ increases in the augmented pumping region $(\Delta p<0)$. It can be viewed from Fig. $1 \mathrm{~b}$ 
Fig. 1 a-f Variations in pressure rise $\Delta p$ for different flow parameters (a)

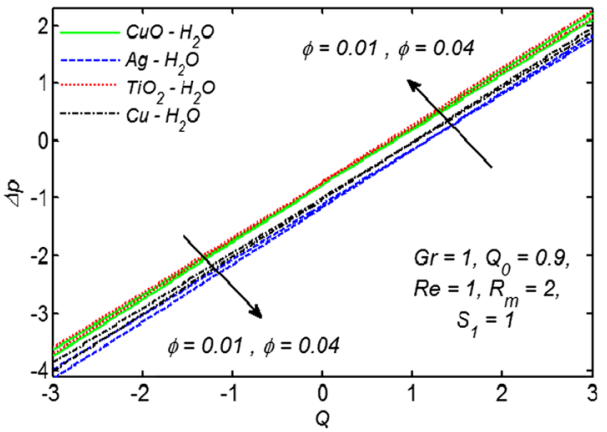

(c)

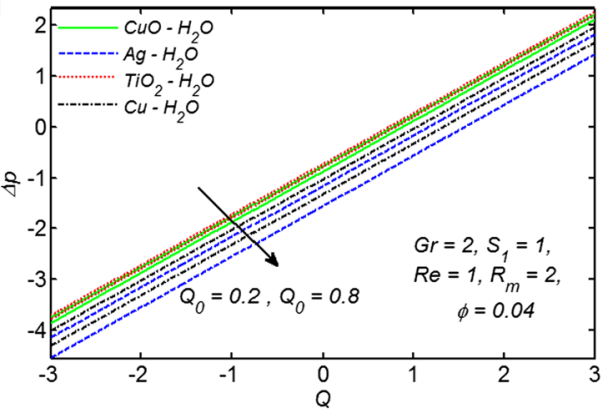

(e)

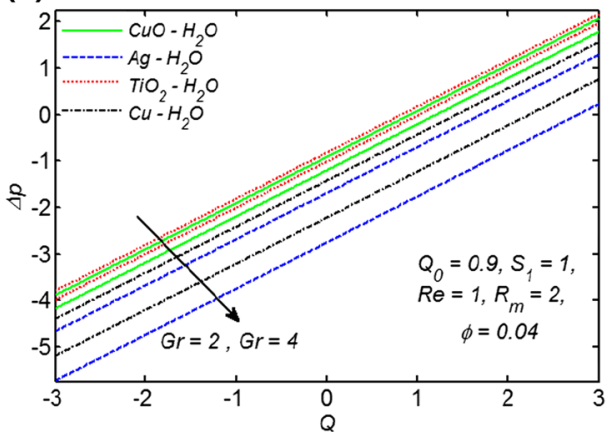

(b)

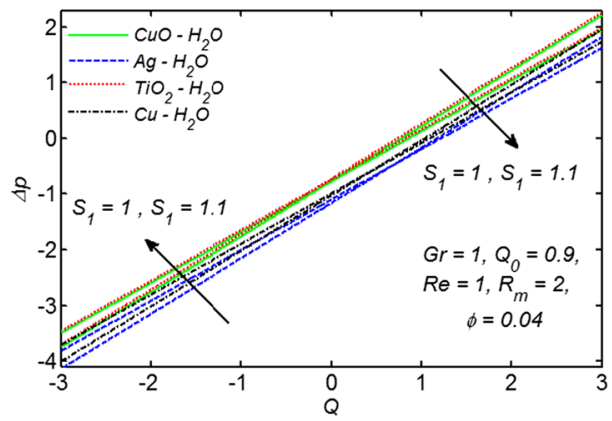

(d)

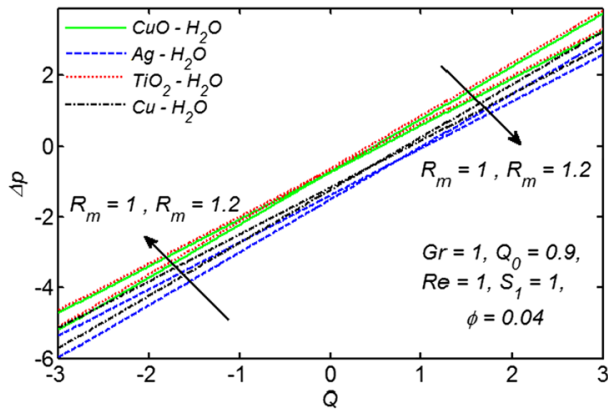

(f)

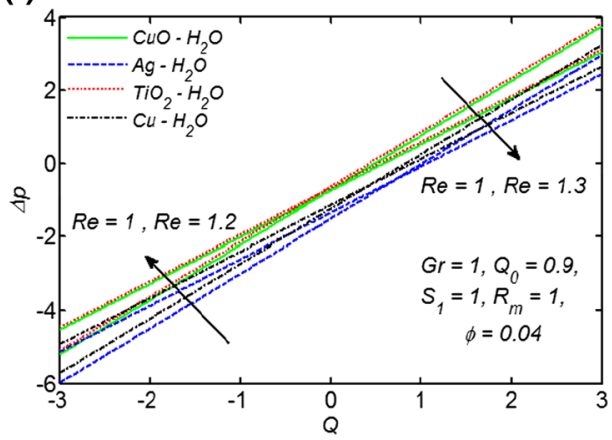

that $\Delta p$ will show the opposite behavior of $S_{1}$ as observed in Fig. 1a; one can see that from Fig. 1c by increasing $Q_{0}$, $\Delta p$ decreases throughout the domain. In Fig. 1d, it is seen that $\Delta p$ decreases with increasing effects of $R_{\mathrm{m}}$ for all four cases in the region $(\Delta p>0)$, where $\Delta p$ decreases in the region $(\Delta p<0)$. To study the behavior of $G_{\mathrm{r}}$ on pressure rise, we draw a graph as in Fig. 1e, and one can notice that $\Delta p$ shows the same behavior as we see for $Q_{0}$. Figure $1 \mathrm{f}$ shows that pressure rise decreases when we increase $R e$ in the peristaltic pumping region and pressure rise increases when we increase $R e$ in the Augmented pumping region. From Fig. 2a, one can see that the pressure gradient $\mathrm{d} p /$ $\mathrm{d} x$ decreases with increase in $\varphi$. The variations in $Q_{0}$ and $R_{\mathrm{m}}$ give the same behavior on the pressure gradient graph as seen for $S_{1}$; See Fig. 2b-d. For an increase in all flow parameters pressure gradient increases. We can see the impact of parameters $G_{\mathrm{r}}$ on the variation of pressure gradient $\mathrm{d} p / \mathrm{d} x$ from Fig. $2 \mathrm{e}$ it is noted that pressure gradient is decreases as increases of $G_{\mathrm{r}}$. From Fig. 2f, one can see that $\mathrm{d} p / \mathrm{d} x$ increases by increasing $R e$. Figure $3 \mathrm{a}$ presents the effects of temperature $\theta$ for the different values of volume fraction $\varphi$. It is observed that as we increases $\varphi$, the temperature also increases. Figure $3 b$ shows that temperature profile increases with an increase in heat generation parameter.

The expression for the magnetic force function $\Phi$ against the space variable $y$ for different values of $E$ and $R_{\mathrm{m}}$ is shown in Fig. 4a, b, respectively. It is observed from the figures that with the increase of $E, \Phi$ decreases and the opposite behavior is noticed for $R_{\mathrm{m}}$.

It is observed from Fig. 5a that the velocity profile decreases near the right wall, but increases near the left wall of the channel with increasing value of $\varphi$. We present Fig. $5 \mathrm{~b}$ to obtain the variation of velocity profile $u$ for varying 
Fig. 2 a-f Variations in pressure gradient $\mathrm{d} p / \mathrm{d} x$ for different flow parameters (a)

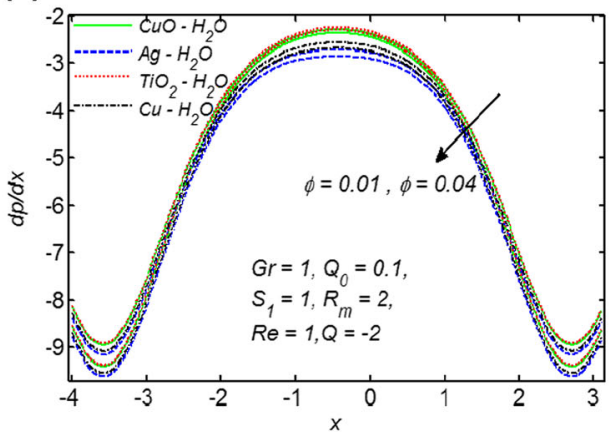

(c)

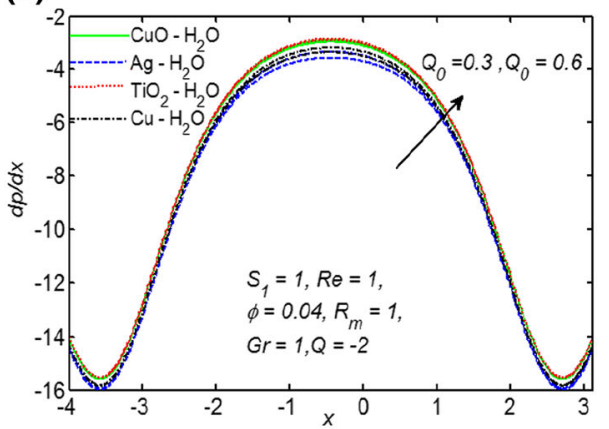

(e)

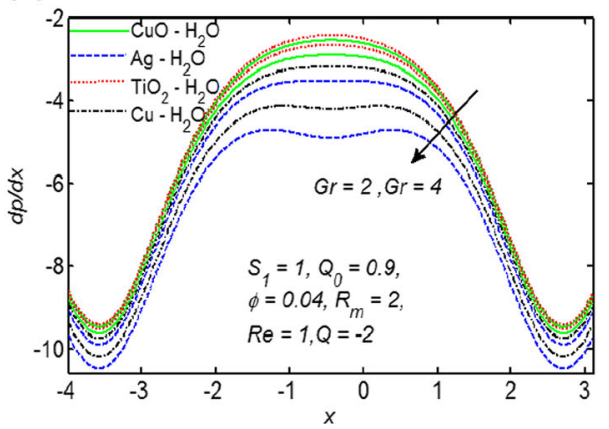

(a)

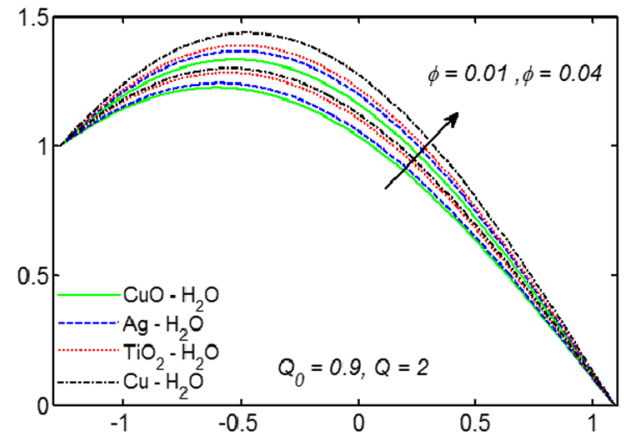

(b)

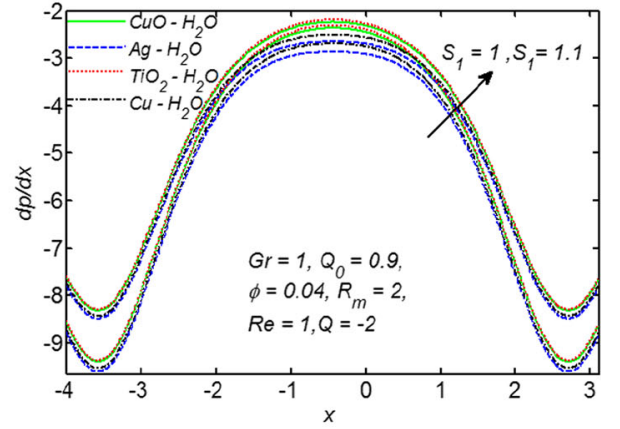

(d)

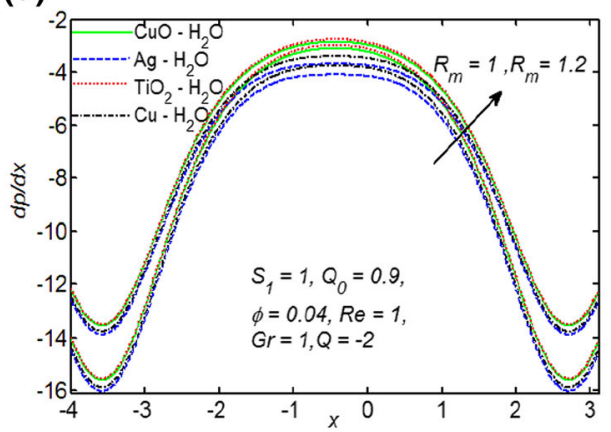

(f)

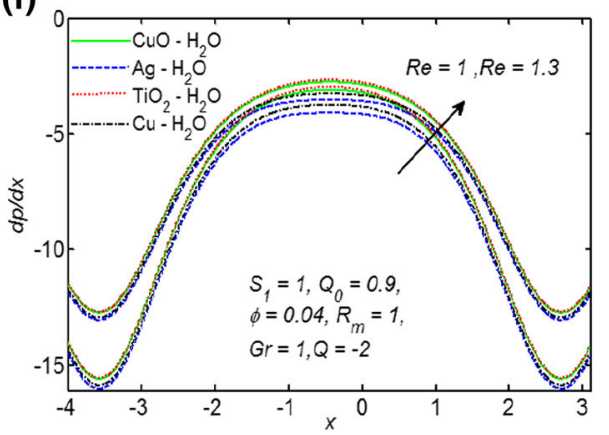

(b)

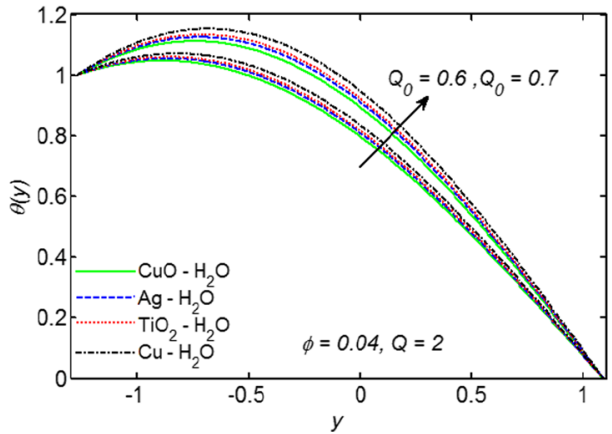

magnitudes of parameters $S_{1}$. It shows that the velocity increases with increases of $S_{1}$ throughout the channel. From Fig. 5c, we study the effect of the behavior of $Q_{0}$ on the velocity profile $u$. it is observed that near the walls, the velocity profile decreases, but at the center of the channel the velocity profile increases by increasing $Q_{0}$. It is also seen that in the cases of $\mathrm{CuO}-\mathrm{H}_{2} \mathrm{O}$ and $\mathrm{Ag}-\mathrm{H}_{2} \mathrm{O}$, parameter $Q_{0}$ does not gives as much variation on velocity as in the cases of $\mathrm{Cu}-$ 
Fig. 4 a, b Variations in induced MHD profile $\Phi$ for different flow parameters

Fig. 5 a-e Variations in velocity profile $u$ for different flow parameters (a)

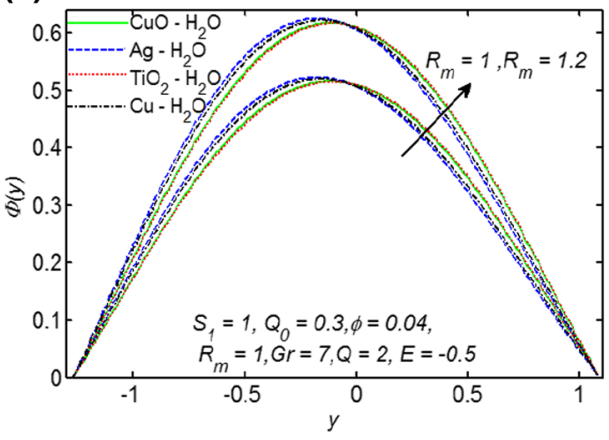

(a)

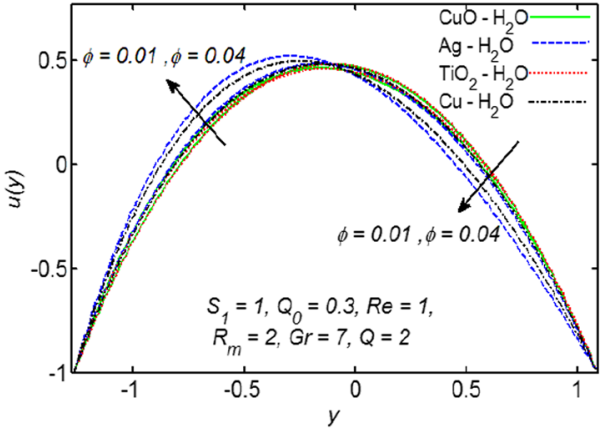

(c)

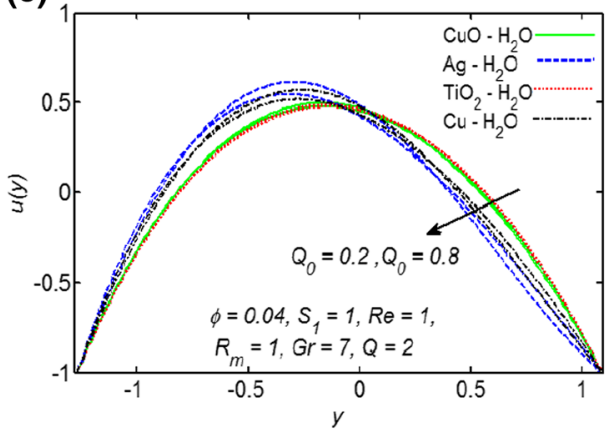

(e)

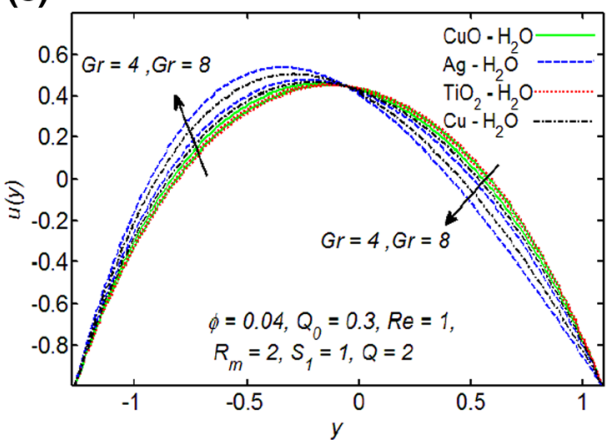

(b)

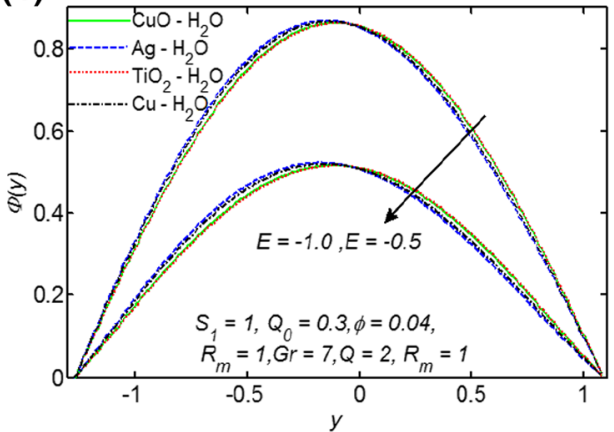

(b)

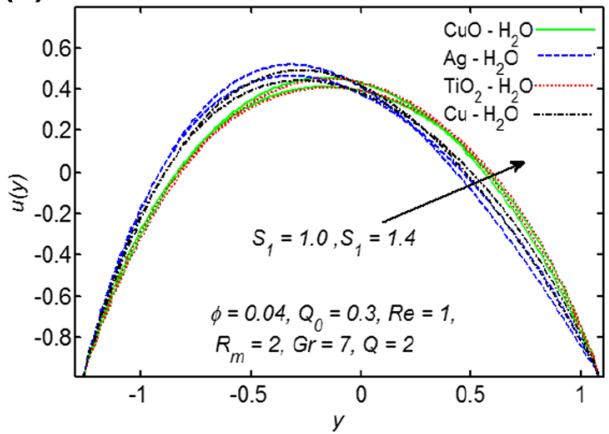

(d)

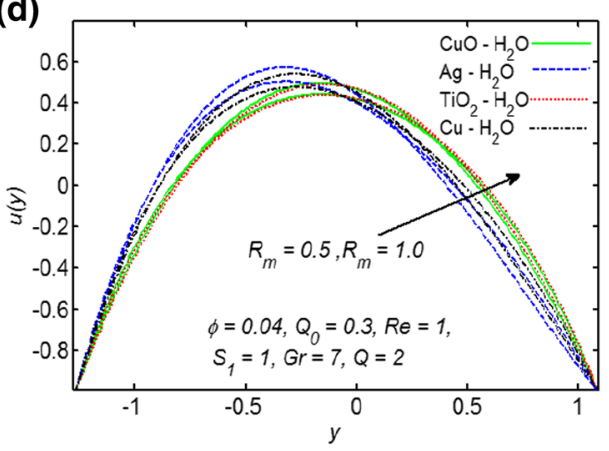

(f)

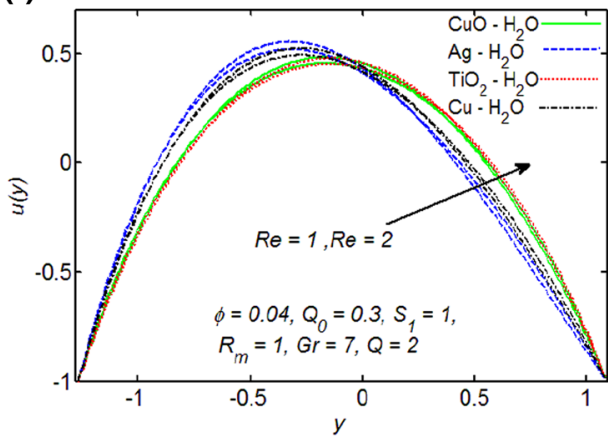

$\mathrm{H}_{2} \mathrm{O}$ and $\mathrm{TiO}_{2}-\mathrm{H}_{2} \mathrm{O}$. Figure $5 \mathrm{~d}$ shows the effect of $R_{\mathrm{m}}$ on the velocity profile. It is observed that near the left wall, the velocity profile decreases by increases in $R_{\mathrm{m}}$, but near the right wall we noticed the opposite behavior of velocity profile. From Fig. 5e, we observe the effect of the behavior of
$G_{\mathrm{r}}$ on the velocity profile. It shows that near the left wall, the velocity profile increases with increases of $G_{\mathrm{r}}$ and near the right wall the velocity profile decreases. We show in Fig. $5 f$ the behavior of the velocity profile with increases in $R e$. It was observed that as we increase the values of $R e$, the 
(a)

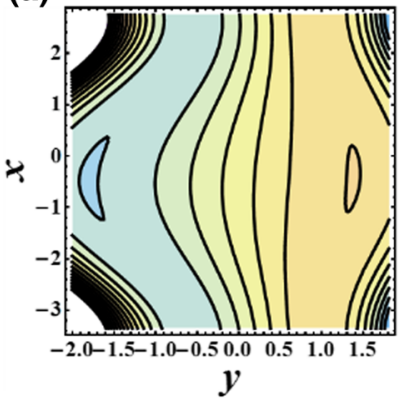

(e)

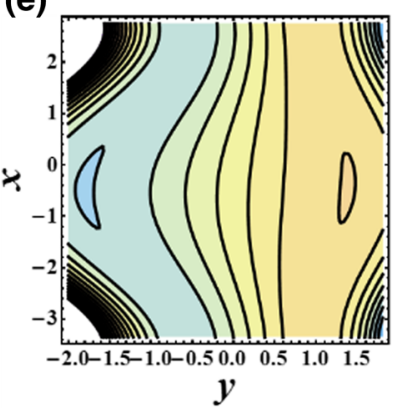

(b)

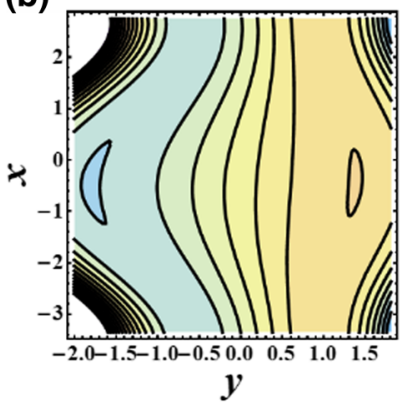

(f)

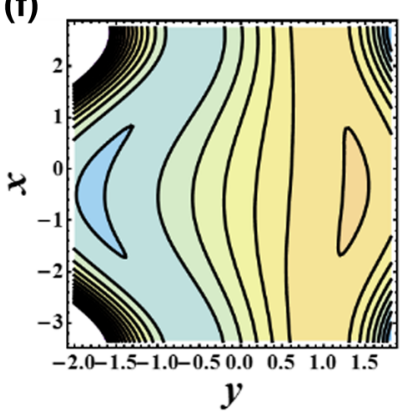

(c)

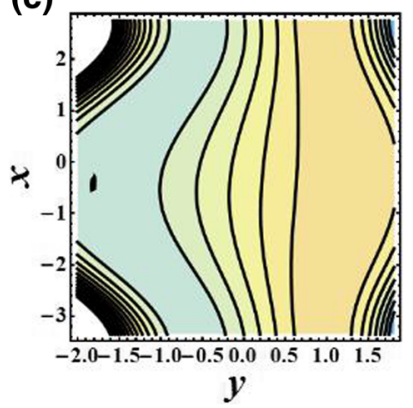

(g)

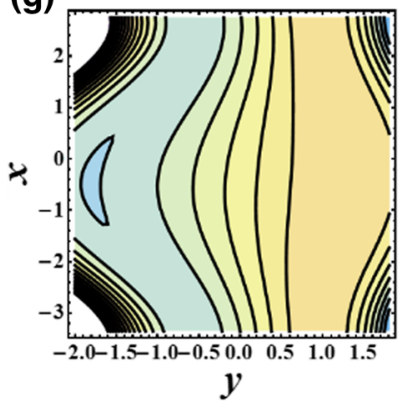

(d)

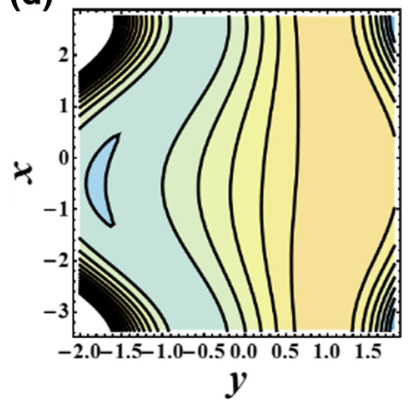

(h)

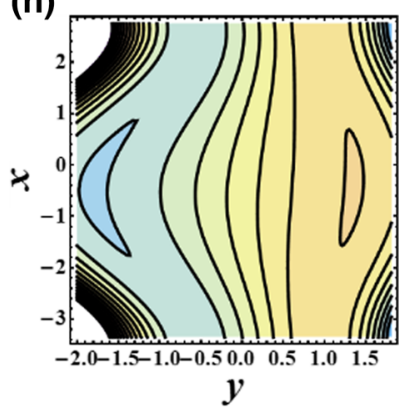

Fig. 6 Streamlines for different values of $\varphi$. a For $\varphi=0.01\left(\mathrm{CuO}-\mathrm{H}_{2} \mathrm{O}\right)$, b $\varphi=0.04\left(\mathrm{CuO}-\mathrm{H}_{2} \mathrm{O}\right)$, c $\varphi=0.3$, d $\varphi=0.4$. The other parameters are $Q=2, \omega=0.3, a=0.2, b=0.4, d=1, \mathrm{Gr}=1, R_{\mathrm{m}}=1, S_{1}=2, \operatorname{Re}=1, Q_{0}=0.1$

(a)

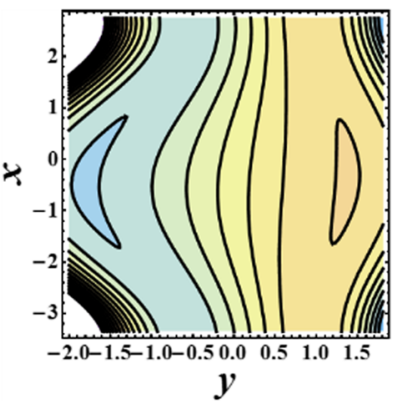

(e)

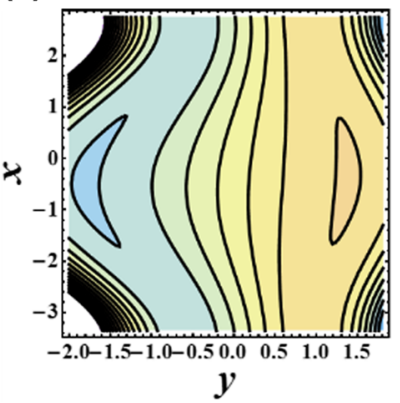

(b)

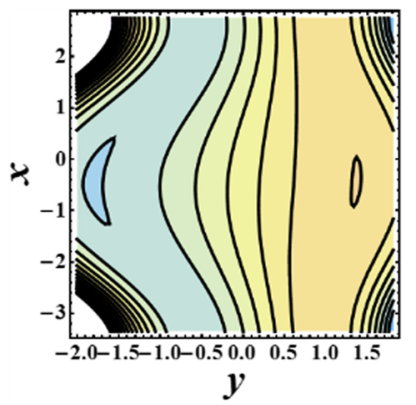

(f)

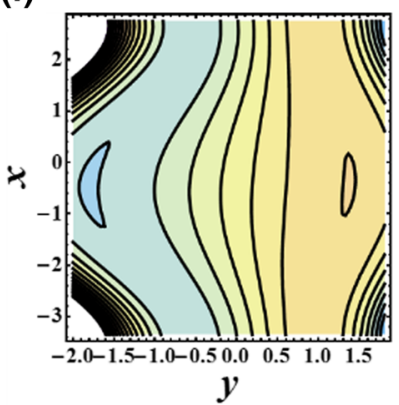

(c)

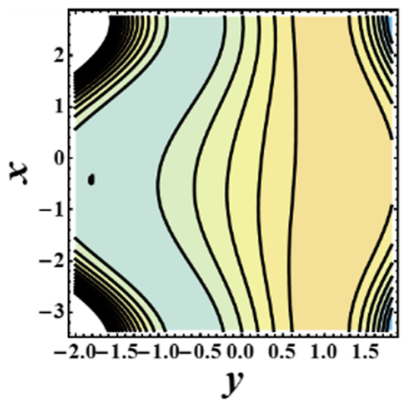

(g)

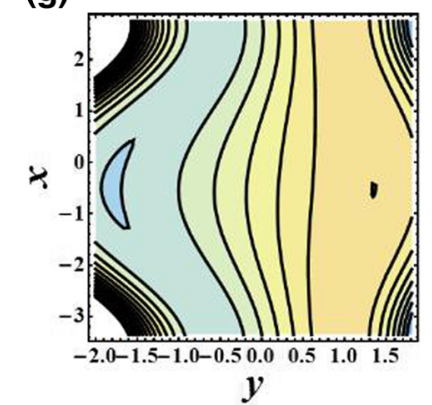

(d)

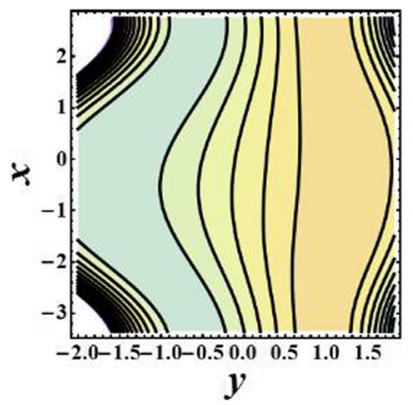

(h)

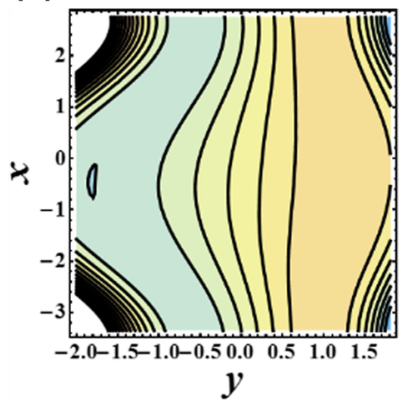

Fig. 7 Streamlines of copper-water nanofluid for different values of Gr. a For $\mathrm{Gr}=1$, b $\mathrm{Gr}=2$, $\mathbf{c} \mathrm{Gr}=3$, d Gr $=4$. The other parameters are $Q=2, \omega=0.3, a=0.2, b=0.4, d=1, \varphi=0.4, R_{\mathrm{m}}=1, S_{1}=2, \operatorname{Re}=1, Q_{0}=0.1$

velocity profile $u$ does not change near the left wall, but decreases at the middle of wall and increases near the right wall of the channels.
A very interesting phenomenon in fluid transport is trapping. The formation of an internally circulating bolus of the fluid by closed streamlines is called trapping and this 
(a)

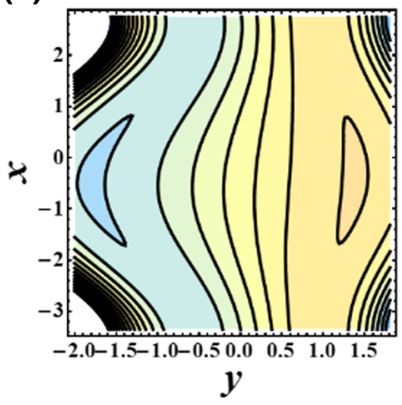

(e)

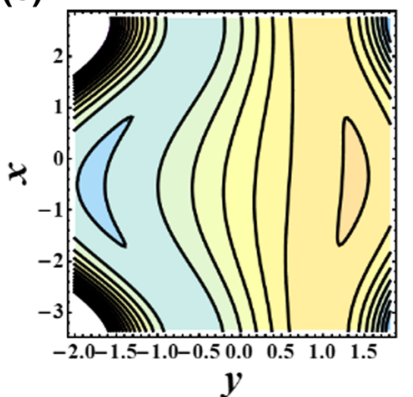

(b)

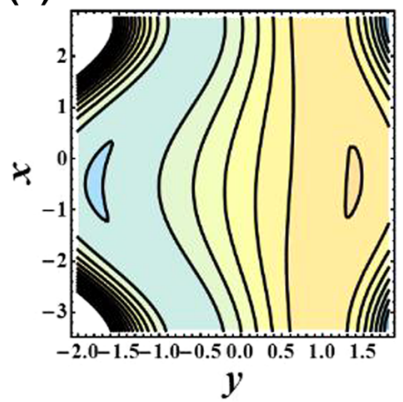

(f)

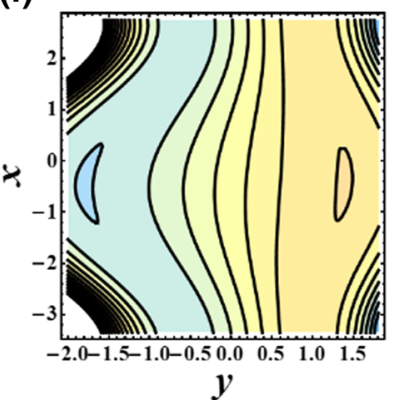

(c)

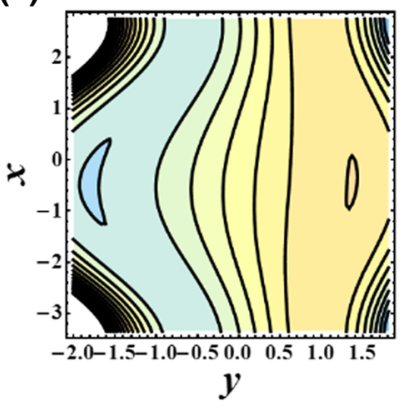

(g)

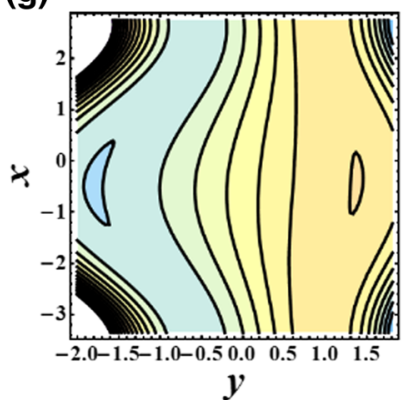

(d)

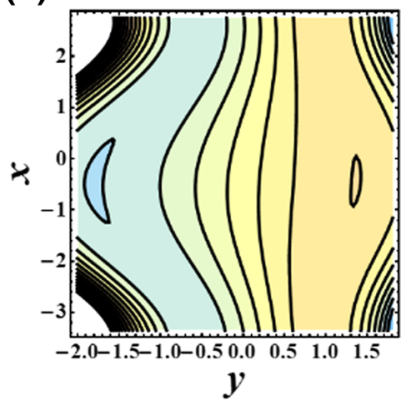

(h)

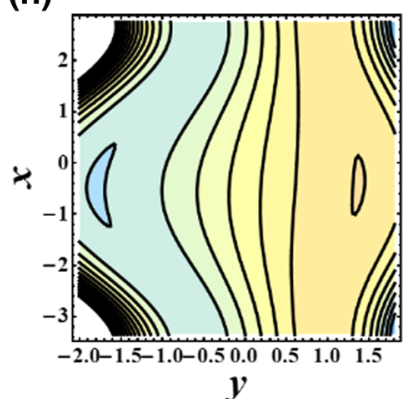

Fig. 8 Streamlines of water for different values of $\mathrm{Gr}$. a For $\mathrm{Gr}=1, \mathbf{b} \mathrm{Gr}=2, \mathbf{c} \mathrm{Gr}=3, \mathbf{d} \mathrm{Gr}=4$. The other parameters are $Q=2, \omega=0.3$, $a=0.2, b=0.4, d=1, \varphi=0.4, R_{\mathrm{m}}=1, S_{1}=2, R e=1, Q_{0}=0.1$

trapped bolus is pushed ahead along the peristaltic wave with the speed of wave. The bolus described as a volume of fluid bounded by closed streamlines in the wave frame is moved as a wave pattern. Figure 6 shows typical contour maps for the streamlines with two values of $\varphi$ ( $\varphi=0.01, \varphi=0.04$ ), Fig. 7 shows the contour maps for the streamlines with two values of $G_{\mathrm{r}}\left(G_{\mathrm{r}}=2, G_{\mathrm{r}}=4\right)$ and Fig. 8 shows contours for the streamlines with two values of $R_{\mathrm{m}}\left(R_{\mathrm{m}}=2.0, R_{\mathrm{m}}=2.1\right)$ for all four type of fluids $\left(\mathrm{CuO}-\mathrm{H}_{2} \mathrm{O}, \mathrm{Ag}-\mathrm{H}_{2} \mathrm{O}, \mathrm{TiO}_{2}-\mathrm{H}_{2} \mathrm{O}, \mathrm{Cu}-\mathrm{H}_{2} \mathrm{O}\right)$. Figure $6 \mathrm{a}, \mathrm{b}$ shows the streamlines for $\mathrm{CuO}-\mathrm{H}_{2} \mathrm{O}$. It is noticed that the bolus becomes large with greater values of $\varphi$. Figure $6 \mathrm{c}, \mathrm{d}$ shows the streamlines for $\mathrm{Ag}-\mathrm{H}_{2} \mathrm{O}$ and it is noticed that the number of bolus increases for higher values of $\varphi$. Figure $6 \mathrm{e}$, $\mathrm{f}$ shows the streamlines for $\mathrm{TiO}_{2}-\mathrm{H}_{2} \mathrm{O}$ and it is seen that the bolus becomes large with larger values of $\varphi$. Figure $6 \mathrm{~g}$, h shows the streamlines for $\mathrm{Cu}-\mathrm{H}_{2} \mathrm{O}$, and it is seen that the number of bolus increases. Figure $7 \mathrm{a}, \mathrm{b}$ shows the streamlines for $\mathrm{CuO}-\mathrm{H}_{2} \mathrm{O}$ and it is observed that the bolus becomes smaller with greater values of $G_{\mathrm{r}}$. Figure $7 \mathrm{c}$, $\mathrm{d}$ shows the streamlines for $\mathrm{Ag}-\mathrm{H}_{2} \mathrm{O}$ and it is noticed that the number of bolus decreases for higher values of $G_{\mathrm{r}}$. Figure 7e, f shows the streamlines for $\mathrm{TiO}_{2}-\mathrm{H}_{2} \mathrm{O}$ and it is shown that the bolus becomes small with larger values of $G_{\mathrm{r}}$. Figure $7 \mathrm{~g}$, h shows the streamlines for $\mathrm{Cu}-\mathrm{H}_{2} \mathrm{O}$ and it is noticed that the number of bolus decreases with greater values of $G_{\mathrm{r}}$. Figure 8a, b shows the streamlines for $\mathrm{CuO}-$
$\mathrm{H}_{2} \mathrm{O}$. Figure 8c, d shows the streamlines for $\mathrm{Ag}-\mathrm{H}_{2} \mathrm{O}$. Figure 8e, f shows the streamlines for $\mathrm{TiO}_{2}-\mathrm{H}_{2} \mathrm{O}$ and it is noticed that the bolus becomes large with greater values of $\varphi$. Figure $8 \mathrm{c}$, d shows the streamlines for $\mathrm{Ag}-\mathrm{H}_{2} \mathrm{O}$ and it was noticed that the number of bolus increases for higher values of $\varphi$. Figure 8e, f shows the streamlines for $\mathrm{TiO}_{2}-$ $\mathrm{H}_{2} \mathrm{O}$ and Fig. $8 \mathrm{~g}, \mathrm{~h}$ shows the streamlines for $\mathrm{Cu}-\mathrm{H}_{2} \mathrm{O}$. One can observe that the size of the bolus becomes small with large values of $R_{\mathrm{m}}$.

\section{Conclusion}

The interaction of nanoparticles for peristaltic flow with the induced magnetic field is discussed. The key points are observed as follows:

1. The pressure rise decreases with the increasing effects of $R_{m}$.

2. The pressure gradient decreases with increases in $G_{\mathrm{r}}$.

3. Near the walls, the velocity profile decreases, but at the center of the channel the velocity profile increases by increasing $Q_{0}$.

4. As we increases the values of $R e$, the velocity profile does not change near the left wall, but at the middle of the wall the velocity decreases and near the right wall of the channels the velocity increases. 
5. In the cases of $\mathrm{CuO}-\mathrm{H}_{2} \mathrm{O}$ and $\mathrm{Ag}-\mathrm{H}_{2} \mathrm{O}$, parameter $Q_{0}$ does not give as much variation in velocity as in the cases of $\mathrm{Cu}-\mathrm{H}_{2} \mathrm{O}$ and $\mathrm{TiO}_{2}-\mathrm{H}_{2} \mathrm{O}$.

6. With the increases of $E$, the magnetic force function decreases and the opposite behavior is noticed for $R_{\mathrm{m}}$.

7. As we increase $\varphi$, the temperature also increases.

8. The streamlines for $\mathrm{CuO}-\mathrm{H}_{2} \mathrm{O}$ show that the bolus becomes large with greater values of $\varphi$.

9. The streamlines for $\mathrm{Cu}-\mathrm{H}_{2} \mathrm{O}$, show that the number of bolus decreases with greater values of $G_{\mathrm{r}}$.

Open Access This article is distributed under the terms of the Creative Commons Attribution 4.0 International License (http:// creativecommons.org/licenses/by/4.0/), which permits unrestricted use, distribution, and reproduction in any medium, provided you give appropriate credit to the original author(s) and the source, provide a link to the Creative Commons license, and indicate if changes were made.

\section{References}

Abu-Nada E (2009) Effect of variable viscosity and thermal conductivity of Al2O3-water nanofluid on heat transfer enhancement in natural convection. Int J Heat Fluid Flow 30:679-690

Abu-Nada E (2010) Effects of variable viscosity and thermal conductivity of $\mathrm{CuO}$ - water nanofluid on heat transfer enhancement in natural convection: mathematical model and simulation. J Heat Transf 132:052401

Akbar NS (2014) Peristaltic Sisko Nano fluid in an asymmetric channel. Appl Nanosci 4:663-673

Akbar NS, Khan ZH (2015) Metachronal beating of cilia under the influence of Casson fluid and magnetic field. J Magn Magn Mater 378:320-326

Akbar NS, Raza M, Ellahi R (2014a) Interaction of nano particles for the peristaltic flow in an asymmetric channel with the induced magnetic field. Eur Phys J Plus 129:155

Akbar NS, Nadeem S, Khan ZH (2014b) Thermal and velocity slip effects on the MHD peristaltic flow with carbon nanotubes in an asymmetric channel: application of radiation therapy. Appl NanoSci 4:849-857

Akbarinia A, Behzadmehr A (2007) Numerical study of laminar mixed convection of a nanofluid in horizontal curved tubes. Appl Therm Eng 27:1327-1337

Choi SUS (1995) Enhancing thermal conductivity of fluids with nanoparticle. ASME Fluids Eng Div 231:99-105

Ellahi R, Rahman SU, Nadeem S, Akbar NS (2014) Blood flow of nano fluid through an artery with composite stenosis and permeable walls. Appl Nanosci 4:919-926

El-Shehawey EF, Husseny SZA (2002) Peristaltic transport of a magneto-fluid with porous boundaries. Appl Math Comput 129:421-440

Ghasemi B, Aminossadati SM (2010) Brownian motion of nanoparticles in a triangular enclosure with natural convection. Int $\mathrm{J}$ Therm Sci 49:931-940

Ibrahim FS, Hamad MAA (2006) Group method analysis of mixed convection boundary layer flow of a micropolar fluid near a stagnation point on a horizontal cylinder. Acta Mech 181:65-81
Jaffrin MY, Shapiro AH (1971) Peristaltic pumping. Ann Rev Fluid Mech 37:13-37

Jang SP, Choi SUS (2007) Effects of various parameters on nanofluid thermal conductivity. ASME J Heat Transf 129:617-623

Jou RY, Tzeng SC (2006) Numerical research of nature convective heat transfer enhancement filled with nanofluids in rectangular enclosures. Int Commun Heat Mass Transf 33:727-736

Koo J, Kleinstreuer C (2004a) A new thermal conductivity model for nanofluids. J Nanopart Res 6:577-588

Koo J, Kleinstreuer C (2004b) A new thermal conductivity model for nanofluids. J Nanoparticle Res 6:577-588

Koo J, Kleinstreuer C (2005) Laminar nanofluid flow in microheatsinks. Int J Heat Mass Transf 48:2652-2661

Latham TW, Fluid Motion in a Peristaltic Pump, MS. Thesis, Massachusetts Institute of Technology, Cambridge, 1966

Li AA, Nesteron NI, Malikova SN, Kilatkin VA (1994) The use of an impulse magnetic field in the combined therapy of patients with stone fragments in the upper urinary tract. Vopr Kurortol Fizide. Lech Fiz Kult. 3:22-24

Mekheimer KHS (2004) Peristaltic flow of blood under effect of a magnetic field in a non-uniform channel. Appl Math Comput 153:763-777

Mekheimer KHS (2008a) Effect of the induced magnetic field on peristaltic flow of a couple stress fluid. Phys Lett A 372(23):4271-4278

Mekheimer KHS (2008) Peristaltic Flow of a Magneto-Micropolar Fluid: Effect of Induced Magnetic Field. J Appl Math. Article ID 570825, 23 pages

Mekheimer KHS, AL-Arabi TH (2003) Non-linear peristaltic transport of MHD flow through a porous medium. Int J Maths Sci 26:1663-1682

Nadeem S, Riaz A, Ellahi R, Akbar NS (2014a) Mathematical model for the peristaltic flow of Jeffrey fluid with nano particles phenomenon through a rectangular duct. Appl Nanosci 4:613-624

Nadeem S, Riaz A, Ellahi R, Akbar NS (2014b) Mathematical model for the peristaltic flow of nanofluid through eccentric tubes comprising porous medium. Appl Nanosci 4:733-743

Nadeem S, Riaz A, Ellahi R, Akbar NS (2014c) Effects of heat and mass transfer on peristaltic flow of a nanofluid between eccentric cylinders. Appl Nanosci 4:393-404

Palm S, Roy G, Nguyen CT (2006) Heat transfer enhancement with the use of nanofluids in a radial flow cooling system considering temperature dependent properties. Appl Therm Eng 26:2209-2218

Sheikholeslami M, Gorji-Bandpy M (2014) Free convection of ferrofluid in a cavity heated from below in the presence of an external magnetic field. Powder Technol 256:490-498

Sheikholeslami M, Gorji-Bandpay M, Ganji DD (2012a) Magnetic field effects on natural convection around a horizontal circular cylinder inside a square enclosure filled with nanofluid. Int Commun Heat Mass Transf 39:978-986

Sheikholeslami M, Gorji-Bandpy M, Ganji DD, Soleimani S, Seyyedi SM (2012b) Natural convection of nanofluids in an enclosure between a circular and a sinusoidal cylinder in the presence of magnetic field. Int Commun Heat Mass Transf 39:1435-1443

Sheikholeslami M, Gorji-Bandpy M, Soleimani S (2013) Two phase simulation of nanofluid flow and heat transfer using heatline analysis. Int Commun Heat Mass Transf 47:73-81

Sheikholeslami M, Gorji-Bandpy M, Ganji DD (2014a) Lattice Boltzmann method for MHD natural convection heat transfer using nanofluid. Powder Technol 254:82-93 
Sheikholeslami M, Bandpy MG, Ellahi R, Zeeshan A (2014b) Simulation of MHD CuO-water nanofluid flow and convective heat transfer considering Lorentz forces. J Magn Magn Mater 369:69-80

Sheikholeslami M, Ganji DD, Javed MY, Ellahi R (2015) Effect of thermal radiation on magnetohydrodynamics nanofluid flow and heat transfer by means of two phase model. J Magn Magn Mater $374: 36-43$
Srivasta LM, Agrawal RP (1980) Oscillating flow of a conducting fluid with a suspension of spherical particles. J Appl Mech 47:169-199

SUD et al (1997) Pumping action on blood by a magnetic field. Bull Math Biol 39:385-390 